\title{
A Study of Effects of Kids' Athletics Exercises on Academic Achievement and Self-esteem
}

\author{
Suat Utkan Çalık, Hacı Ahmet Pekel", Latif Aydos \\ Sport Sciences Faculty, Gazi University, Turkey
}

Copyright $\bigcirc 2018$ by authors, all rights reserved. Authors agree that this article remains permanently open access under the terms of the Creative Commons Attribution License 4.0 International License

\begin{abstract}
The aim of this study is to examine the effects of kids' athletics training program on their academic achievement and self-esteem. The kids' athletics training program is implemented for 14 weeks. The study consists of one experiment group (n: 95, 52 M, 43 F, age 10,92 \pm 0,61 years old) and one control group (n: $148,73 \mathrm{M}, 75 \mathrm{~F}$, age 10,90 $\pm 0,63$ years old). These two groups consist of totally 243 children. The "Cooper Smith Self-esteem Questionnaire-Children's Form" whose reliability and validity was proved by Pişkin in 1996 is used to measure the self-esteem [1]. Academic achievement values are identified by students' school reports. Following the pre-test, Kids athletics program whose duration is 60 minutes is implemented 3 days in a week for 14 weeks. In the last test, self-esteem and academic achievement measures of the students is done again. In the statistical analysis of the self-esteem and academic achievement of the experiment and control groups, it is seen that there is a significant increase in the total self-esteem (p:0,0377) and general self-esteem (p:0,0421) of the experimental group. Moreover, a significant increase is detected in Physical Education and Sports (p:0,0015), Music (p:0,0224), Turkish (p:0,0047) and Foreign Language (p:0,000) grades.
\end{abstract}

Keywords Kids' Athletics, Academic Achievement, Self-esteem

\section{Introduction}

Athletics creates an excellent environment that allows children to interact with their peers because of the various contest areas [2]. International Association of Athletics Federations (IAAF) has developed a new concept of athletics that focuses on the developmental needs of children as a result of countless research and studies that have designed contests for children entirely in a way that continues to inspire children's sporting enthusiasm and mutual interaction [2]. The IAAF backed work in spring 2001 was completed in 2005, and this project was named "IAAF KIDS 'ATHLETICS" [2]. The term is expressed as kids' athletics and athletics Game.

The athletics games will provide children with the opportunity to make the most of the beneficial practice of Athletics, in terms of Health, Education, and Self-fulfillment [2]. The concept that expressed in sense of making use of the literature in our work is physical activity and it's one of the most basic human functions [3]. National and international organizations have expressed the human health benefits of physical activity which is accepted all over the world.

In addition to the contributions of physical activity for child's body, the search for the effect of academic achievement and self-esteem development has attracted many researchers.

Success; is a measure or indication of how much an individual benefits from a particular course or academic program in the school setting. Success in school; it can be considered as the average of the scores of the students from the courses in an academic program. Academic success; it is considered successful if the goals set in the teaching process have been attained, and unsuccessful if not. The exams in schools that determine the level of learning of students are actually successful [4].

Self-esteem is a personal judgment of value, expressed in the attitudes of the individual towards him [5]. Self-esteem is related to emotional states of individuals at a high level, since it means the individual's emotions about himself / herself. While individuals with high self-esteem can be said to be in a more positive mood than those who have positive emotions about themselves, the same is true for individuals with low self-esteem [6].

Self-esteem has a positive contribution to psychological well-being and person's behavior [7], individual's compliance and mental health [8]. Self-esteem has a positive effect on the school-related life as well as the positive effect of individuals on their psychological and mental health. Those with high self-esteem show much more perseverance when faced with difficulties [9]. 


\section{Material and Method}

\subsection{Working Group}

The study was conducted in Ankara, Necip Fazil Kısakürek Secondary School in the spring term of 2016-2017 academic year. The study, consisted of one experiment group (n: 95, $52 \mathrm{M}, 43 \mathrm{~F}$, age 10,92 $\pm 0,61$ years old) and one control group (n: 148, $73 \mathrm{M}, 75 \mathrm{~F}$, age $10,90 \pm 0,63$ years old). The experiment and control groups include healthy children who had never been involved in athletics before. A written approval form has been obtained from the families of all the students who participated in the study.

\subsection{Training Method}

A training program consisting of 60 minutes of lessons per day for 3 days a week was applied for 14 weeks so that all disciplines of athletics could be taught to secondary school students.

Twelve themes were used in the prepared training program. These themes are; introduction, 2 lessons per hour, the course objectives, the sharing of the plan, the creation of course rules, the assignment of research tasks to the students, introduction of the athletics, the rules of the game, giving information about the materials and branches used in athletics, the organizations organized in athletics, Paralympic branches in athletics, hygiene and security, puzzle activities related to materials used in athletics.

I am preparing to Run; Warming and cooling practices for athletics such as jogging (5-10') and stretching (5-10'). By the help of running drills and games, running coordination and techniques are tried to be improved. Running drills like skips, high knee, heel to butt, straight leg, power skip and ankle stretch were done. Each of them was applied slowly in a range of 15 meters and at least 2 times. These activities continued for 3 lesson hours.

I learn running; Short distance running, medium distance running, long distance running, obstacle running and relay running were applied with the help of games, hurdles and slalom. These games include Sprint/Hurdles Shuttle Relay, Sprint/Slalom, Formula One (Sprint, Hurdles and Slalom Running) and 8' Endurance Race. These activities continued for 3 lesson hours. 8' Endurance Race was applied for one lesson, other games were applied 2 times in two lessons. Hurdles that height 40-50-60 cm were used.

I learn jumping; Long jump, triple jump, high jump, pole jumping topics were applied with Pole Long Jumping, Triple Jumping within a limited area, Exacting Long Jumping, Rope Skipping, Forward Squad Jumping, Cross Hopping, Ladder Running games designed for children. These activities continued for 3 lesson hours.

I learn to throw; throwing events for children, target throwing, kids' javelin throwing, knee throwing, kids' discus throwing, overhead backward throwing and rotational throwing events for 6 lesson hours is applied by repeating the games. The medicine ball is $0,5-1 \mathrm{~kg}$, the javelin is max $0,5 \mathrm{~kg}$, medicine ball with handle is $550 \mathrm{gr}$, soft discus is 300-500 gr. Each of these games was applied one lesson session and last lesson a mix of these games was applied.

I Develop Competition Events; Group / team competitions related to $1 \mathrm{x}$ running, $1 \mathrm{x}$ throwing, $1 \mathrm{x}$ jumping were applied. These activities continued for 6 lessons. Each game was applied one repetition every lesson.

I am a Team/Group Member; Working groups / teams are identified and until last lesson these groups were remained same. Role sharing of working groups is done. (Roles: coach, team captain, referee, statistician, press officer). The responsibilities of the roles have been checked in detail. Running, throwing and jumping games are repeated with roles included. These activities continue for 3 lessons.

I am fast and in Rhythm; Kids' Athletics games for speeding, position of start at short distance runs (high, low and starting block) and reaction exercises in short distance runs with coaches of groups / teams are executed. These activities are applied for 2 lessons and during lessons 20 minutes warm up is applied by guiding of coaches. Team roles are distributed. The training of hurdles and hurdles are carried out in cooperation with the teams' coaches and teacher. The specialties of running from starting block to first hurdle, hurdles pass, running between hurdles and last run from the last hurdle to finish are represented and applied by the teacher. These activities continued for 3 lesson hours.

I improve my skills of jumping and throwing; long jump skills are taught (approaching, jumping, flying and putting), and the long jump skill are repeated in the presence of the coaches of the group / teams. The techniques of shot put, soft discus, javelin, medicine ball are taught. The student are given 2,5 lesson times for applying. Group discussion is conducted (biomechanical principles for athletics) at last lesson for 30 minutes. These activities continued for 3 lessons.

I'm durable; medium-long distance runs are taught and practiced. The teacher gives information about high staring position, medium-long distance running strategies and tactics (pulse measuring ways, arrangement of training and resting time). The proposed training method emphasizes the speed control and the aerobic abilities of the participants. The participants are taught an energy saving strategy at the beginning of the race with the help of this event. In first lesson continuing running is applied at $60 \%$ of max heart rate for 20 minutes. The 50-200 meters interval workout is done in the second lesson, the students' heart rates are increased for a short period. The groups/teams apply 20-30 minutes of warm-up and running drills with team coaches. The group / teams are repeated in the middle and long distance runs in the presence of their coaches for 2 lessons. The rules of flag change are given 
and flag change techniques are applied for 30 minutes in the last lesson. The group / teams repeat the techniques of flag change in the presence of their coaches. Group discussion is conducted (psychological characteristics necessary for success in athletics) in the last lesson for 30 minutes. These activities continued for 3 lessons.

We Try Our Skills as a Team; in the first lesson short/medium/long distance running competitions $(60 \mathrm{~m}$, $60 \mathrm{~m}$. hurdles, $1000 \mathrm{~m}$.) are done. In the second lesson; throwing competitions and long jump competitions are applied. In the last lesson relay competitions $(4 \times 75 \mathrm{~m})$ are executed between teams. The roles of referee, registration, coach etc. in all competitions are performed by students. These activities continue for 3 lessons.

I participate in the festival; Competitions between teams (multiple branch applications), execution of responsibilities of students who has different roles, result activities (team competitions) and award ceremony are performed. The competition is applied with one branch related to throwing, jumping and running. In the first lesson; Sprint/Slalom, Forward Squat Jumping, Kids Javelin Throwing. In the second lesson; Formula One (Sprint-, Hurdles- and Slalom Running), Triple Jumping within a limited area, Overhead Backward Throwing. These activities continue for 2 lessons.

The practice stages of the themes are built on Kids' Athletics games for jumps, jumps and throws, as set by the IAAF $[2,10]$ and in the athletics module [11] prepared by Ministry of Education for the secondary schools.

\subsection{Data Collection Tools}

\subsubsection{Self Esteem}

The Coopersmith Self-Esteem Scale-Children's Form which was validated by PISKIN [1], is applied at the beginning and end of the study. Permission for use of the scale is given by Professor Doctor Metin PISKIIN.

\subsubsection{Academic Achievement}

The term "Academic Achievement" is grade point average of Turkish, Math, Social, Foreign language, Religion Culture and Ethics, Physical education and Sports, Information Technologies and software, Music lessons. The success of students is determined with exam by teachers. The teachers are not included in our study because our study can be limited by the teacher attitude depending on his tendency of given high marks. The academic achievement of the experimental group and the control group participating in the study is determined by the school reports of the students who requested voluntarily at the end of the academic year 2016-2017. No identifiers, school numbers or code numbers of students are not used, as communicated to students and parents at the beginning of our work.

\subsubsection{Statistical Analysis of Data}

Minitab 16 package program is used for the statistical analysis of the findings of the study. The comparative analysis of the descriptive statistics of the experimental and control groups for the beginning and end of the semester is tabulated. The normality distribution of all data used in the study is analyzed by Anderson Darling normality test. The statistical comparison of the academic achievement and self-esteem values of the pre-test and post-test of the Experiment Group and the Control Group are performed by non-parametric Mann-Whitney test. The Mann-Whitney test is preferred because the data are not normally distributed and the values contain different sample numbers. In the statistical analysis of the data, the confidence interval was accepted as 95\% (p significance level 0.05).

\section{Findings}

\subsection{Comparison of Anthropometric Changes of Experimental and Control Group}

Table 1. Comparison of the anthropometric measurements of the experimental and control groups with the Mann-Whitney test

\begin{tabular}{|c|c|c|c|c|c|c|}
\hline & iables & Min. & Max. & Avr. \pm SS & $\mathrm{W}$ & $\mathrm{p}$ \\
\hline \multirow{4}{*}{$\begin{array}{l}\text { Height } \\
(\mathrm{cm})\end{array}$} & Exp. Gr. Pre-test & 126 & 163 & $144,09 \pm 8,10$ & & \multirow{4}{*}{0,2067} \\
\hline & Exp. Gr. Post-test & 128 & 164 & $144,72 \pm 6,33$ & 12164,5 & \\
\hline & Cnt. Gr. Pre-test & 125 & 167 & $143,75 \pm 8,13$ & & \\
\hline & Cnt. Gr. Post-test & 127 & 170 & $144,27 \pm 7,09$ & & \\
\hline \multirow{4}{*}{$\begin{array}{c}\text { Weight } \\
(\mathrm{kg})\end{array}$} & Exp. Gr. Pre-test & 25 & 67 & $39,1 \pm 9,25$ & \multirow{4}{*}{10273,5} & \multirow{4}{*}{$0,0107 *$} \\
\hline & Exp. Gr. Post-test & 26 & 70 & $39,26 \pm 9,60$ & & \\
\hline & Cnt. Gr. Pre-test & 25 & 75 & $39,7 \pm 9,9$ & & \\
\hline & Cnt. Gr. Post-test & 25 & 79 & $40,29 \pm 10,25$ & & \\
\hline \multirow{4}{*}{$\begin{array}{l}\text { BFP } \\
(\%)\end{array}$} & Exp. Gr. Pre-test & 10,76 & 37,9 & $21,32 \pm 5,60$ & \multirow{4}{*}{9902,0} & \multirow{4}{*}{$0,0020^{*}$} \\
\hline & Exp. Gr. Post-test & 10,2 & 39,8 & $21,63 \pm 6,43$ & & \\
\hline & Cnt. Gr. Pre-test & 8,9 & 43,3 & $22,46 \pm 6,78$ & & \\
\hline & Cnt. Gr. Post-test & 9,2 & 43,3 & $23,00 \pm 6,56$ & & \\
\hline
\end{tabular}

$\mathrm{p}<0,05^{*}$, BFP: body fat percentage, Exp. Gr.: Experimental Group., Cnt. Gr.: Control Group 
As seen in Table 1, the experimental and control group students there were statistically significant differences between the pre and post-test differences of body weight ( $\mathrm{p}$ $<0,05)$ and VAT $(p<0,05)$ ratios.

\subsection{Comparison of Experimental and Control Groups' Self-esteem Survey Changes}

The Mann Whitney test is used to compare the results of the pre-test and post-test questionnaires with respect to General Self-Esteem, Academic Self-Esteem, Social Self-Esteem, Home-Family Self Esteem and Total Self-Esteem for the experimental and control group. Parametric tests cannot be used because the number of samples in the experimental group and control group is different; non-parametric the Mann Whitney test was applied to these comparisons.

Our hypothesis is that for these 5 headings;

Ho: M1=M2 (there is no difference between the two factors)

$\mathrm{H} 1: \mathrm{M} 1>\mathrm{M} 2$ (there is a difference between the two factors)

M1: Experiment group pre-course and post-course survey changes differences

M2: Control group pre-course and post-course survey changes differences

Table 2. Mann-Whitney test results on the comparison of the self-esteem differences of the experimental and control group

\begin{tabular}{|c|c|c|}
\hline Variables & W & p \\
\hline General Self-Esteem & 12461,0 & $0,0421^{*}$ \\
\hline Academic Self-Esteem & 12020,0 & 0,1849 \\
\hline Social Self-Esteem & 11887,0 & 0,2589 \\
\hline $\begin{array}{c}\text { Home-Family } \\
\text { Self-Esteem }\end{array}$ & 12245,0 & 0,0934 \\
\hline Total Self-Esteem & 12488,5 & $0,0377^{*}$ \\
\hline
\end{tabular}

When the analysis results are examined, it can be said that the General Self-Esteem $(0,0421)$ and Total Self-Esteem $(0,0377)$ values of $\mathrm{P}<0.05$ are statistically significant in the $95 \%$ confidence interval.

The calculation of total self-esteem is the sum of the other four variables. While there is no statistically significant difference between the three variables except General Self-Esteem, the sum of the four variables contains a significant difference, it is thought that the differences in each subgroup are due to cumulative effect.

The value of $\mathrm{P}$ of the variables of academic self-esteem $(0,1849)$, social self-esteem $(0,25889)$ and home-family self-esteem $(0,0934)$ is greater than 0.05 , it means that the effect of athletic practices on these variables is insignificant.

\subsection{Comparison of Academic Achievement Changes of Experiment and Control Group}

For the experimental and control group, first semester and second semester in total of 8 subtitles, which are composed of Turkish, Mathematics, Information Technologies and Software, Physical Education and Sports, Social Studies, Foreign Language, Music and Religion Culture and Moral Information courses. Parametric tests cannot be used because the numbers of experimental and control groups are different for evaluating the differences of course grades so non-parametric Mann Whitney test was applied.

Our hypothesis is that for these 8 headings;

Ho: M1=M2 (there is no difference between the two distributions)

H1: $M 1 \neq M 2$ (not equal difference between the two factors)

M1: Experiment group pre-course and post-course grade differences

M2: Control group pre-course and post-course grade differences

Table 3. Mann-Whitney test results on the comparison of the academic achievement differences of the experimental group and the control group

\begin{tabular}{|c|c|c|c|c|}
\hline \multicolumn{2}{|c|}{ Variables } & $\mathbf{N}$ & Avr. & $\mathbf{p}$ \\
\hline \multirow{2}{*}{ Turkish } & Experimental Group & 95 & 1,167 & \multirow{2}{*}{0,0094} \\
\hline & Control Group & 148 & $-0,75$ & \\
\hline \multirow{2}{*}{ Math } & Experimental Group & 95 & 0,000 & \multirow{2}{*}{0,2646} \\
\hline & Control Group & 148 & $-0,369$ & \\
\hline \multirow{2}{*}{ Social } & Experimental Group & 95 & 0 & \multirow{2}{*}{0,3411} \\
\hline & Control Group & 148 & $-0,417$ & \\
\hline \multirow{2}{*}{$\begin{array}{c}\text { Foreign } \\
\text { language }\end{array}$} & Experimental Group & 95 & 5 & \multirow{2}{*}{0,0000} \\
\hline & Control Group & 148 & 1 & \\
\hline \multirow{2}{*}{$\begin{array}{c}\text { Religion } \\
\text { Culture and } \\
\text { Ethics } \\
\end{array}$} & Experimental Group & 95 & 1 & \multirow{2}{*}{0,4471} \\
\hline & Control Group & 148 & 2,125 & \\
\hline \multirow{2}{*}{$\begin{array}{c}\text { Physical } \\
\text { education } \\
\text { and Sports }\end{array}$} & Experimental Group & 95 & 1,667 & \multirow[b]{2}{*}{0,0030} \\
\hline & Control Group & 148 & 0,667 & \\
\hline \multirow{2}{*}{$\begin{array}{l}\text { Information } \\
\text { Technologies } \\
\text { and software }\end{array}$} & Experimental Group & 95 & 0 & \multirow{2}{*}{0,8509} \\
\hline & Control Group & 148 & 1 & \\
\hline \multirow{2}{*}{ Music } & Experimental Group & 95 & 0 & \multirow{2}{*}{0,0448} \\
\hline & Control Group & 148 & 0 & \\
\hline
\end{tabular}

When the analysis results are examined, it expresses that the difference between the grades of Physical Education and Sports $(0,0030)$, Music $(0,0448)$, Turkish $(0,0094)$ and Foreign Language $(0,0000)$ meaning so Ho's hypothesis is rejected and the $\mathrm{H} 1$ hypothesis is accepted. This difference is statistically significant in the $95 \%$ confidence interval. In the analysis, results of the other lessons the fact that the value of $\mathrm{P}$ is bigger by 0.05 means that we accept the Ho hypothesis.

The determining of academic achievement is done by teachers not by researchers. This situation initially leads us to analyze whether there is a change or not in academic achievement. After the first analyze, it is obvious that there is a correlation between academic achievement and training, either in positive or negative way. The academic achievements of Physical Education and Sport, Music, Turkish and Foreign Language courses are changing. Is the change positive or negative? So we need a new 
analysis.

Our hypothesis is that for these 4 headings;

Ho: $\mathrm{M} 1=\mathrm{M} 2$ (there is no difference between the two factors)

H1: M1>M2 (there is a difference between the two factors)

Table 4. Mann-Whitney test results on the comparison of the academic achievement differences of the experimental group and the control group

\begin{tabular}{|c|c|c|c|c|}
\hline & Variables & $\mathbf{N}$ & Avr. & $\mathbf{p}$ \\
\hline \multirow{2}{*}{ Turkish } & Experimental Group & 95 & 1,167 & \multirow{2}{*}{0,0047} \\
\hline & Control Group & 148 & $-0,75$ & \\
\hline \multirow{2}{*}{$\begin{array}{c}\text { Foreign } \\
\text { language }\end{array}$} & Experimental Group & 95 & 5 & \multirow{2}{*}{0,0000} \\
\hline & Control Group & 148 & 1 & \\
\hline \multirow{2}{*}{$\begin{array}{c}\text { Physical } \\
\text { Education } \\
\text { and Sports }\end{array}$} & Experimental Group & 95 & 1,667 & \multirow{2}{*}{0,0015} \\
\hline & Control Group & 148 & 0,667 & \\
\hline \multirow{2}{*}{ Music } & Experimental Group & 95 & 0 & \multirow{2}{*}{0,0224} \\
\hline & Control Group & 148 & 0 & \\
\hline
\end{tabular}

When the analysis results is examined, it is found that the difference between the grades of Physical Education and Sports Course $(0,0015)$, Music $(0,024)$, Turkish $(0,0047)$ and Foreign Language $(0,0000)$ was statistically significant $\mathrm{p}<0.05)$. That is, our $\mathrm{H} 1$ hypothesis is accepted. It shows that there is a change in the positive direction and this difference is statistically significant in the $95 \%$ confidence interval.

\section{Discussion and Conclusion}

Purpose of the study; 60-minute athletics lessons that are administered 3 days a week for 14 weeks investigate the impact of program on academic achievement and self-esteem.

It is expected that the practices of athletics applied by the students in the experimental group will affect their self-esteem from personal characteristics. At the same time Self-esteem is a student-centered issue that affects academic achievement [12].

A significant change was found in the general self-esteem and total self-esteem values of the experimental group students in the analysis conducted in our study. The changes in the values of Academic Self-Esteem, Social Self-Esteem, and Home-Family Self-Esteem, which are the other sub-items of self-esteem, are unimportant. When the literature is examined, many researches come out from the past. In the finding of Korkmaz; Statistically significant difference is presented among the general self-esteem, social self-esteem and academic self-esteem scores obtained from the pre-test and post-test when the sport activities held in the summer sports school examined the effect of the children on the self-esteem [13]. In the $\mathrm{PhD}$ dissertation conducted at Grand Canyon University, it was found that the students who are in the upper level of physical fitness higher and more significant test scores than the sedan peers when they compared the high self-esteem of the high school students who are in the dance competitions and the upper level students with the sedentary life in 2013 [14]. In a similar study; In an observational study conducted by CEKIN in 2015, the physical activity status of 175 female and 198 male Sports Science Faculty (20 years old) was determined. Subjects who had a physically active life in the analysis performed showed higher self-esteem than those who were not active [15]. Contrary to the findings of our study, Hubbs and colleagues did not find a significant correlation between physical activity and self-esteem in their study [16]. Studies show that the effects of physical training on self-esteem are positive. There are studies say that there is no effect [17-19], but there is no evidence to support a negative effect. Therefore, it is evaluated that the findings obtained in our study are similar to the literature.

In the academic achievement analysis, which is another subject of our study, it can be said that the kids' athletics practices are an important influence on Physical Education and Sport, Music, Foreign Language and Turkish grades of the experimental group. When the literature is investigated, many researches come out from the past, and many scientific publications in the literature are similar, as it is our study. In the study conducted in 1966 in America, a positive correlation was found in the effect of physical activity on Academic Achievement [20]. Seefeldt and Haubenstricker; in 1986, they noticed that physical activity indirectly affected cognitive performance in children with a positive relationship with one's self-confidence. Participation in physical education programs could contribute to making students more familiar with academic processes [21]. In a cross-sectional study by Dwyer and colleagues, they found a positive correlation between the rate of physical activity and academic achievement [22]. Another similar study was conducted in 2002 by 954,000 students from the California Department of Education. The results of the study showed that there was a positive relationship between the high academic performance and the student's fitness level in 3 different age groups [23]. In $\mathrm{PhD}$ study at Walden University in 2016, the effect of 5 days and 55 minutes of physical education lessons per academic week was investigated during 1 academic year. As a result of the research, the experimental group showed a small but significant positive correlation in "Reading and Math skills" [24]. Studies show that the effects of physical training on academic achievement are positive. There are studies say that there is no effect [25-27] but there is no evidence to support a negative effect.

In the literature, it is noteworthy that the studies that deal with the relationship between physical activity, academic achievement and self-esteem. A study by Howells and Bowen explored the development of 
self-esteem and academic success in a small school with 200 pupils, a student named John nickname, who received special athletics lessons during the academic year. John is a child who has low self-esteem and is not very successful in academic lectures, physically bigger than friends. I have John for 5 months, every Friday afternoon 30 minutes for a total of 600 minutes. Training was done on discus throw and shot put. At the end of the term; John is raised literacy and mathematic grades and led to a small but significant increase in self-esteem [28].

A study was conducted on 531 students in Portugal with an average age of $9,13.74 \%$ of the students regularly perform physical activity and $26 \%$ do not. Students' academic achievement and self-esteem are also measured and noted. It has not been noted that there is a definite relationship between the regular physical activity and academic performance and self-esteem in the analysis performed. However, it was noted that students with the highest number of hours per week of physical activity had significantly higher levels of academic achievement and self-esteem compared to students who had no weekly regular physical activity or had less hours [29].

There are many studies in the literature that show a relationship between physical activity and self-esteem and between physical activity and academic achievement. Despite the positive relationship between physical activity and academic achievement and self-esteem in past studies [28,30,31], very little studies have been found on the type, severity and duration of physical activity that may be appropriate $[32,33]$. In this respect, it is evaluated that it is important that our work is focused on kids' athletics, that a specific program is introduced, and that there are no studies that investigate the effects of kids' athletic practices alone. Therefore, the effects of 14 week-long kids' athletics practices on children's academic achievement and self-esteem were examined.

The aim of this study was to investigate analysis of the pretest and posttest data of the experimental and control groups; there was a significant change in the general self-esteem and total self-esteem values. It has been found through previous experimental studies that young people's participation in physical activity is positively associated with various mental health issues [34-36]. When we think about the results of our experimental study, it can be said that sport is important for children and adolescents not only in terms of health and physical development but also in terms of personality development and mental health.

A statistically significant increase is found in Physical Education and Sport, English, Music and Turkish grades in the academic achievement analysis. It is possible that the change in physical education and sports grade is associated with the training program being performed and in conclusion the IAAF Kids' Athletics can be more effective than the traditional physical education teaching method, in terms of improving the secondary school students' physical fitness. It is evaluated that the significant change in the Turkish grade may be due to the positive effect of the socialization from the gains of physical activity.

The effect of Kids' Athletics training program on success of music lesson may be important for expert of music science. But, this subject can have 2 results. Is it the effect of music to performance or vice versa? It is generally believed that there is effect of music on performance.

Another topic is the increase in the score of foreign language lesson. This can be said to be similar to the literature [37]. But; the result of our study can be explained with the attitude of the teacher.

As a result we do not know the extent to which the teachers' personality, their effect, course success measurement methods and the learning climate provided to their classes, influenced the results in academic achievement. This effect could be thought as the limitation of our study. The other limitation is that we do not know the extent to which maturation has influenced the students' improvement in academic achievement and self-esteem because they are children in the age of development. The last limitation of this study is that it focused on the effect of the program's structural design and its content on informing students' about all details of athletics, and we actually see our study as a different making one.

As a result, kids' athletic practices show a positive effect on academic achievement and self-esteem. For this reason, it is suggested that schools should include kids' athletics program in physical education classes.

Kids' Athletics teach athletics with a game centered method so the study highlights the influence of teaching athletics with games, on contrary to the other teaching style, in terms of motivating students' participation and increasing their desire to athletics.

In future studies on athletics, it is thought that the examination of the effect of kids' athletics on mental and emotional development in different age groups will contribute to the planning of the education of all age groups.

\section{REFERENCES}

[1] Piskin, M. (1996). Self-esteem and locus of control of secondary school children both in england and turkey (Order No. U074446). Available from ProQuest Dissertations \& Theses Global. (301505043). Retrieved from

https://search.proquest.com/docview/301505043?accountid $=11054$

[2] International Association of Athletics Federations (IAAF). (2006). IAAF Kids' Athletics For Children -a team event for children (2nd Edition), Monaco: International Association of Athletics Federations, 1-82. 
[3] World Health Organization. (2006). The world health report 2006: working together for health. World Health Organization.

[4] Özgüven İ.E. (1998). Bireyi tanima teknikleri. Ankara: Pdrem Yayınları, 5.

[5] Coopersmith, S. (1967). The antecedents of self-esteem. San Francisco: W.H. Freeman.

[6] Baumeister R.F., \& Twenge J.M. (2003). The social self. Handbook of psychology, 327-352. URL:http://www.com municationcache.com/uploads/1/0/8/8/10887248/handbook of_psychology_volume_5 personality_and_social_psych ology_2003.pdf

[7] Brown J.D. \& Mankowski T.A. (1993). Self-esteem, mood, and self-evaluation: changes in mood and the way you see you. Journal of Personality And Social Psychology, 64(3), 421. doi:10.1037/0022-3514.64.3.421

[8] Taylor, S. E., \& Brown, J. D. (1988). Illusion and well-being: A social psychological perspective on mental health. Psychological Bulletin, 103(2), 193-210. http://dx.doi.org/10.1037/0033-2909.103.2.193

[9] McFarlin, D. B., Baumeister, R. F. and Blascovich, J. (1984), On knowing when to quit: Task failure, self esteem, advice, and nonproductive persistence. Journal of Personality, 52: 138-155. doi:10.1111/j.1467-6494.1984.tb 00349.x

[10] Gozzoli C., Simohamed J., El-Hebil A.M. (2006). "Educational Cards Kids' Athletics", IAAF. URL: http:// www.iaaf.org/mm/Document/imported/37264.pdf.

[11] Milli Eğitim Bakanlığı(MEB). (2013). Spor ve Fiziki Etinlikler Dersi: Atletizm Modülü. Ankara: Talim ve Terbiye Kurulu Başkanlığı, 2-124.

[12] Şevik, Y. (2014). İlköğretim müdür ve müdür yardımcılarının öğrencilerin akademik başarısını etkileyen faktörlere ilişkin görüşleri ile akademik başarısına katkıları. Yayınlanmamış Yüksek Lisans Tezi, Mehmet Akif Üniversitesi, Burdur.

[13] Korkmaz N. (2015). Yaz spor okulları ile çocukların benlik saygısı arasındaki ilişki. Uludağ Üniversitesi Eğitim Fakültesi Dergisi, 20(1),

49-65.URL:http://dergipark.ulakbim.gov.tr/uefad/article/vi ewFile/5000152356/5000138167

[14] Yates, K. L. (2013). A comparison of self-esteem levels on competition cheerleaders and their peers (Order No. 3597633). Available from ProQuest Dissertations \& Theses Global. (1458315585). Retrieved from https://search.proquest.com/docview/1458315585?accounti $\mathrm{d}=11054$

[15] Cekin R. (2015). Psychological Benefits of Regular Physical Activity: Evidence from Emerging Adults. Universal Journal of Educational Research, 3(10), 710-717.URL:

https://files.eric.ed.gov/fulltext/EJ1077621.pdf

[16] Hubbs A., Doyle E.I., Bowden R.G. \& Doyle R.D. (2012). Relationships among self-esteem, stress, and physical activity in college students. Psychological Reports, 110(2), 469. doi: 10.2466/02.07.09.PR0.110.2.469-474

[17] Marsh, H.W. and Peart, N.D. (1988). Competitive and cooperative physical fitness training programs for girls: Effects on physical fitness and multidimensional self-concepts. Journal of Sport and Exercise Psychology, 10(4), 390-407. https://doi.org/10.1123/jsep.10.4.390

[18] Wood, C., Angus, C., Pretty, J., Sandercock, G., and Barton, J. (2013). A randomised control trial of physical activity in a perceived environment on self-esteem and mood in UK adolescents. International Journal Of Environmental Health Research, 23(4), 311-320. https://doi.org/10.1080/09603123.2012.733935

[19] Hubbs, A., Doyle, E. I., Bowden, R. G., and Doyle, R. D. (2012). Relationships among self-esteem, stress, and physical activity in college students. Psychological Reports, 110(2), 469. https://doi.org/10.2466/02.07.09.PR0.110.2.4 $69-474$

[20] Gregor J.G. (1966). The relationship between physical fitness and academic achievement. Master Thesis. Central Washington University The Graduate Faculty.URL: https://digitalcommons.cwu.edu/cgi/viewcontent.cgi?articl $\mathrm{e}=1548$ \& context $=$ etd

[21] Haubenstricker, J., \& Seefeldt, V. (1986). Acquisition of motor skills during childhood. Physical activity and well-being, 41-102. URL:

https://files.eric.ed.gov/fulltext/ED289874.pdf\#page=49

[22] Dwyer T., Sallis J.F., Blizzard L., Lazarus R. \& Dean K. (2001). Relation of academic performance to physical activity and fitness in children. Pediatric Exercise Science, 13(3), 225-237. Doi: 10.1123/pes.13.3.225

[23] Scheuer, L. J., \& Mitchell, D. (2003). Does physical activity influence academic performance. The New PE and Sport Dimension, 12. doi=10.1.1.513.9420\&rep=rep1\&type $=$ pdf

[24] Shook, S. U. (2016). The relationship between physical fitness and academic achievement in sixth grade students (Order No. 10103264). Available from ProQuest Dissertations \& Theses Global. (1787830494). Retrieved from

https://search.proquest.com/docview/1787830494?accounti $\mathrm{d}=11054$

[25] Dwyer, T., Coonan, W.E., Leitch, D.R., Hetzel, B.S., and Baghurst, R. (1983). An investigation of the effects of daily physical activity on the health of primary school students in South Australia. International Journal of Epidemiology, 12(3), 308-313. https://doi.org/10.1093/ije/12.3.308

[26] Sallis, J.F., McKenzie, T.L., Kolody, B., Lewis, M., Marshall, S., and Rosengard, P. (1999). Effects of health-related physical education on academic achievement: Project SPARK. Research Quarterly For Exercise and Sport, 70(2), 127-134. https://doi.org/10.1080/02701367.1999.10 608030

[27] Coe, D.P., Pivarnik, J.M., Womack, C.J., Reeves, M.J., and Malina, R.M. (2006). Effect of physical education and activity levels on academic achievement in children. Medicine \& Science in Sports and Exercise, 38(8), 1515-1519.

[28] Howells K \& Bowen J. (2016). Physical Activity and Self-Esteem: "Jonny's Story". Education 3-13, 44(5), 577-590. URL:

https://create.canterbury.ac.uk/id/eprint/17208 
[29] Batista M., Cubo D.S., Honório S., \& Martins J. (2016). The practice of physical activity related to self-esteem and academical performance in students of basic education. Journal Of Human Sport And Exercise, 11(2), 297-310. doi:10.14198/jhse.2016.112.03

[30] Batista, M., Cubo, D. S., Honório, S., and Martins, J. (2016). The practice of physical activity related to self-esteem and academical performance in students of basic education. Journal Of Human Sport And Exercise, 11(2), 297-310. doi:10.14198/jhse.2016.112.03

[31] Harris-Dawson, L.C. (1993). The relationship between physical fitness and attendance in school, academic achievement and self-esteem, Master Thesis, Fort Hays State University School of Education, Kansas, 36-59.

[32] Marsh, H.W. and Peart, N.D. (1988). Competitive and cooperative physical fitness training programs for girls: Effects on physical fitness and multidimensional self-concepts. Journal of Sport and Exercise Psychology, 10(4), 390-407. https://doi.org/10.1123/jsep.10.4.390

[33] Seabra, A.C., Seabra, A.F., Brito, J., Krustrup, P., Hansen, P.R., Mota, J., Rebelo, A., Rêgo, C., and Malina, R.M. (2014). Effects of a 5-month football program on perceived psychological status and body composition of overweight boys. Scandinavian Journal of Medicine and Science in Sports, 24, 10-16. https://doi.org/10.1111/sms.12268

[34] Fredricks, J.A. and Eccles, J.S. (2005). Developmental benefits of extracurricular involvement: Do peer characteristics mediate the link between activities and youth outcomes? Journal of Youth and Adolescence, 34(6), 507-520. https://doi.org/10.1007/s10964-005-8933-5

[35] Miller, K.E., Melnick, M.J., Barnes, G.M., Farrell, M.P., and Sabo, D. (2005). Untangling the links among athletic involvement, gender, race, and adolescent academic outcomes. Sociology of Sport Journal, 22(2), 178-193. https://doi.org/10.1123/ssj.22.2.178

[36] Kiluk, B.D., Weden, S., and Culotta, V.P. (2009). Sport participation and anxiety in children with ADHD. Journal of Attention Disorders, 12(6), 499-506. https://doi.org/10.1177/1087054708320400

[37] Volle, M., Tisal, H., LaBarre, R., Lavallée, H., Shephard, R., Jéquier, J., and Rajic, M. (1984), Required physical activity and psychomotor development of primary school children (in Children and Sport). Berlin: Springer, 53-57. https://doi.org/10.1007/978-3-642-69465-3_7 